\title{
Daubechies Awarded Nemmers Prize
}

Northwestern University has announced that INGRID DAUBECHIES of Duke University has been awarded the 2012 Frederic Esser Nemmers Prize in Mathematics. The Nemmers Prize, one of the largest monetary awards in the United States, honors outstanding achievements in the discipline. Awarded to scholars who have made major contributions to new knowledge or to the development of significant new modes of analysis, the prize carries a cash award of US\$200,000.

Daubechies was honored "for her numerous and lasting contributions to applied and computational analysis and for the remarkable impact her work has had across engineering and the sciences." Daubechies is the academic leader in the broad area of theoretical signal processing. She is world renowned for her many pioneering contributions to the theory and application of wavelets and filter banks.

Her work on wavelets has had a profound impact on the extensive field of mathematical research known as computational harmonic analysis. It has found powerful applications in the areas of data compression, compressed sensing, and digital communications, and it has an impact on a wide range of scientific disciplines. The influence of her work is realized daily in millions of consumer and technological products, including communication systems, medical imaging, seismic exploration, and audio and video coders.

Daubechies's more recent research has focused on discrete geometry, a field which uses very different methods from those in which she has previously worked; this work is motivated by real-world problems in computer animation and biology.

Among her numerous honors, she received the National Academy of Sciences Award in Mathematics in 2000 for her fundamental discoveries on wavelets, which are among the most significant in the history of mathematics. She also was a fellow of the MacArthur Foundation between 1992 and 1997

DOI: http://dx.doi.org/10.1090/noti876 and in 1993 was elected to the American Academy of Arts and Sciences. In 1994 she received the American Mathematical Society Steele Prize for Exposition for her book Ten Lectures on Wavelets. In 1997 she was awarded the AMS Ruth Lyttle Satter Prize in Mathematics, and in 1998 she was elected to the U.S. National Academy of Sciences.

Born in Houthalen, Belgium, she received her B.S. degree in physics in 1975 and her Ph.D. in physics from the Free University Brussels. After teaching at the Free University Brussels for twelve years, she joined AT\&T Bell Laboratories. She joined Princeton in 1993. Between 2004 and 2011 Daubechies was the William R. Kenan Jr. Professor in the mathematics and applied mathematics departments at Princeton, the first-ever female professor of mathematics at Princeton. She is currently the James B. Duke Professor of Mathematics at Duke University.

Northwestern University also announced that Daron Acemoglu, the Elizabeth and James Killian Professor of Economics at the Massachusetts Institute of Technology, was awarded the 2012 Erwin Plein Nemmers Prize in Economics, which also carries a stipend of US $\$ 200,000$.

The Nemmers Prizes are made possible through bequests from the late Erwin E. Nemmers, a former member of the Northwestern University faculty, and his brother, the late Frederic E. Nemmers, both of Milwaukee. The prizes are awarded every other year. Previous Nemmers prize recipients in mathematics are Yuri I. Manin (1994), Joseph B. Keller (1996), John H. Conway (1998), Edward Witten (2000), Yakov G. Sinai (2002), Mikhael Gromov (2004), Robert P. Langlands (2006), Simon Donaldson (2008), and Terence Chi-Shen Tao (2010).

Consistent with the terms of the Nemmers bequests, the Erwin Plein Nemmers Prize in Economics (named in honor of the Nemmerses' father) and the Frederic Esser Nemmers Prize in Mathematics (named by Erwin in honor of his brother) are designed to recognize "work of lasting significance" in the respective disciplines. 